\title{
Study on the Subsidy of Volunteers' Personal Expenses
}

\author{
Jiawei Chen ${ }^{1, a^{*}}$ \\ ${ }^{1}$ School of Public Administration and Political Science and Law, Southwest Jiaotong University, \\ Chengdu 610031, P. R. China \\ a1301027392@qq.com \\ *The Corresponding author
}

Keywords: Volunteer; Personal Expenses; Subsidy

\begin{abstract}
Volunteers are not for any money or material rewards, they volunteer their time, spirit and skills to take part in social public welfare. But it doesn't mean they shouldn't get rewords, the subsidy mentioned in this paper is not the denial of volunteerism, and is also not to give rewords according to work time and workload, but to make up for volunteers' direct costs in voluntary service and give necessary funding support, such as providing accommodation, meals, etc during the process of voluntary, which is a respect for volunteers' labor and a protection for volunteers' right.
\end{abstract}

\section{Introduction}

In order to solve the double dilemma of government and market failure, the third sector who has a strong social function came into being, which laid a good foundation for the development of volunteerism. Volunteerism is the activity what volunteers do,it refers to the behavior of volunteers who use their time, skills, resources and kindness to provide non-profit, unpaid, non-professional assistance to their neighbors, communities and society. As a noble and great cause, volunteerism plays an important role in promoting human glory and traditional virtues of Chinese nation. After the reform and opening up ,our volunteerism was born, and construction of volunteer and youth volunteer began in the 1980s. In 1987, when the first national volunteer service hotline was opened in Guangzhou, after more than 30 years of development and deepening, our volunteer activities got unprecedented development in various fields, volunteer organizations have also gained their own place, and volunteers also gained widespread acceptance as a special career.

Volunteers are not for any money or material rewards, and regardless of the gains and losses of fame and fortune, they volunteer their time, spirit and skills to engaged in social public service and to provide services for the society. Volunteers who do not pursue reword do not mean they should not get reward, Zhihan Wang and Meng Wu think subsizing necessary costs for volunteers and volunteer organations in the process of volunteerism and providing public service(products), is helpful to maintain its normal operation, and they also use the subsidy as an incentive mechanism to recognize the value of the society. In the article of Nonprofit Volunteer Management and Human Resources Development(2009),Zebao Guo believes that volunteer subsidy is an important indicator of volunteer management, Through reimbursement of volunteer activities expenses such as communication fees, basic accommodation and even the minimum cost of living and the purchase of insurance. The subsidy mentioned in this paper is not the denial of volunteerism, and is also not to give rewords according to work time and workload, but to make up for volunteers' direct costs in voluntary service and give necessary funding support ,such as providing accommodation, meals, etc during the process of voluntary, which is a respect for volunteers' labor and a protection for volunteers' right.

\section{The State of Subsidying Volunteers' Personal Expenses in Our Volunteers}

Comparing the status of voluntary service at home and abroad, foreign volunteers have a variety of work arrangements every day with no salary, but many local ngos, government, farms, schools and nature conservation units will provide free accommodation and food. There are three types of 
voluntary subsidy programs for volunteers in China: First, it's relatively common in our country that volunteers' accommodation, tolls and so on are covered by themselves. For example, in 2010, during the Guangzhou Asian Games volunteer service, the Asian volunteers' accommodation and travel expenses should be borne by the volunteers themselves. Second, volunteers' accommodation and travel expenses is partly borne by themselves, such as 2008 Beijing Olympic Games, volunteers' accomodation in Beijing should be provided by themselves, according to the description of a volunteer in Guangzhou, you have to spend your own money to report to Beijing, and then you must pay 3000 yuan for accommodation, it's not clear whether it will provide food, the two sets of volunteer clothing are the only "affordable". Third, there are a small number of organizations and other companys to provide volunteers' expense. This kind of situation is very common in our college students volunteer activities, College students as the main force of volunteers in our country, on the one hand they don't have economic ability, on the other hand, only college students are willing to go to poor areas for volunteer service, The society generally felt that it should be properly subsidized for its actions

Comparating volunteer service regulations in different parts of China, we can find that our local regulations have pointed that our volunteers have right to get help from other organizations and volunteers, but majority of regulations don't make clear what these rights are, and how to subsidize volunteers' expense. Although the government authorities have not explicitly recognized the legal status of volunteer subsidy, with the attention being paid to the needs of volunteers themselves, The subsidy for volunteers has begun to gain attention and is gradually being put on the agenda, Thus, subsidies for volunteers has become a trend.

\section{The Necessity of Subsidying Volunteers' Personal Expenses}

There are three main aspects of whether it should subsidy volunteers' personal expenses. First, whether individual interests and demands should be met or not. Second, discussing the necessity of subsidy volunteers from the perspective of volunteers' own needs. Third, subsidy volunteers are encourage and respect for volunteer work.

First, whether individual interests and demands should be met or not. Individual interests and public interests have always been the focus of academic debate, but the relationship between the two has always been controversial. According to the correct understanding of the interests of the French political thinker, Tocqueville(托克维尔), he proposed three supporting viewpoints. The first is that personal interests are inherently and are difficult to stop; Second, it's not conflict between individual interests and social welfare; Finally, it is pointed out that such individual interests can provide incentives. Since the market economy, the economic rational person hypothesis has been fully embodied, its essence is a kind of individual self-interest rationality. Here self-interest refers to the reasonable self-interest, it combines personal and social interests, rather than extreme egoism. The market economy based on the affirmation of individual interests, which realize the interests of buyers and sellers through price mechanism, is an act of altruism towards self-interest. Market economy as an acceptable form of economy, it focus on the deepest self-interest of people and recognizes and respects the legitimate rights of individuals to pursue their own interests. The volunteers as a social person, clearly have their own needs and have the power to pursue these needs, and this is also in line with self-interest of market economy.

Second, from the perspective of volunteers' own needs, volunteers have the right to receive help from society. In traditional concept, everyone agrees that volunteers are offering compensation services, but with the growing of volunteer team, expanding of service sector, increasing demands of professional volunteers, the cost of volunteer activities will be more and more, and there will be a different understanding of subsidy volunteers. According to the relevant view in the theory of social exchange: Actors are rational, in order to obtain the basic needs of other actors, they should exchange interaction with other actors. As a special action subject, volunteers are also rational. According to Maslow's hierarchy of needs, volunteers to participate in volunteer service activities, also got some own needs, but they are different from their status 
and identity. Therefore, there are different pursuit of material needs and spiritual needs in the volunteer activities, as an social person, volunteers also have the right to get help from the society.

At the same time, especially those who are enthusiastic to help the vulnerable and poor groups, they are not very rich, sometimes they dump everything and all its return is the difficulties and helplessness of the life. The basic subsidy for voluntary is not only contributes to the development of volunteer activities, but also contributes to the humanitarian care of volunteer activities. Anyway, for any volunteers, they have the power to meet their own needs and also have access to get help from society. This kind of needs and help will be different because of personal differences, so in this paper, the subsidy for voluntary service is to meet the basic requirements of the volunteers, so as to carry out volunteer works.

Third, the essence of subsiding volunteers is to encourage volunteer behavior and respect for volunteer labor. Many studies have shown that subsidy for volunteers is an incentive for volunteer behavior, it can spirit volunteers' identity, they think their labor can get affirmation from the organizations, and they will have great enthusiasm to devote into future works. But in some volunteer service, due to lack of finance supports, there is a decline of volunteer enthusiasm. Many volunteers point out that material subsidies are too little, and they have to solve their own accommodation, meals, and ect. Although volunteer activities are unpaid and public welfare, as one volunteer he can accept no reward, but if you are required to pay some expenses during you participate in activities, In the long term, The enthusiasm of the volunteers must be affected.

\section{Conclusion}

Volunteers as an important force in volunteer service, play an important role in the process of volunteer service in China. For a long time, the cognition of volunteers in society is voluntary, unpaid, serviceable and so on, but with the deepening of the market economy, the pursuit of personal interests continue to spawn and there is a different understanding of volunteer subsidies, it is just to make up for volunteers' direct costs in voluntary service and give necessary funding support ,such as providing accommodation, meals, etc during the process of voluntary. This is not a denial of volunteer service and volunteer spirit, but a kind of respect for the volunteer labor, a protection of the rights and interests of volunteers. Volunteer subsidy as an important part of volunteer incentive, In this article, through analyzing the state of the subsidy of volunteers and exploring the necessity of subsidy of volunteers, is beneficial to improving the enthusiasm and participation of volunteers, So as to protect the long-term development of volunteer service, and achieve the prosperity and development of China's volunteer career.

\section{References}

[1] Y.Y Zhang, Library,(2015) No.08,p.12

[2] X.X Wang and P Zhang. Learning And Practice. (2012) No. 11,p.97

[3] Y.Z Liu and Y.F Wu, Youth and the Communist Youth League work, (2011) No. 11,p.49

[4] P Lu. College Students Volunteer Incentive Mechanism Problems and Countermeasures(MS. Xiangtan University, China 2014)

[5] R.J Meng, Chuancheng, (2015) No. 3 ,p.84

[6] Z.B Guo, Journal Of US-China Public Administration, Vol. 5 (2009) No.05,p.1

[7] X.F Liao, Contemporary Educational Science , (2012) No.11,p.32

[8] Z.H Wang and M Wu, Journal of China Youth College for Political Sciences, Vol. 25 (2006) No.02,p.12

[9] Y.C Liu, Chinese Higher Education,(1993) No.06

[10] XY Dang and H Jiang, Public Administration Science,(2010) No. 03,p.43

[11] T.X Liu and Y Zhou, Journal Of Northwest University,(2004) No. 11,p.82

[12] Y Jiang and Q.H Li, Journal of Tibet University, Vol. 29 (2014) No. 02,p.185 